\title{
La otra internacional. Prácticas globales y anclajes nacionales de la liberación homosexual en Argentina y México $(1967-1984)^{*}$
}

\section{The Other Internationale. Global Practices and National Anchors of Homosexual Liberation in Argentina and Mexico (1967-1984)}

\author{
Patricio Simonetto ${ }^{* *}$ \\ (D) https://orcid.org/0000-0001-5906-7072 \\ University College of London-Institute of the Americas \\ patriciosimonetto@gmail.com
}

Resumen: El objetivo de este artículo es estudiar las prácticas, las redes locales y transnacionales, los traductores sociales y las tensiones de los movimientos de liberación homosexual de Argentina y México. Para cumplimentar este objetivo se estudia un valioso material de archivo que incluye publicaciones de

* Esta investigación fue financiada por la fundación Teixidor y el Instituto de Investigaciones Históricas de la Universidad Nacional Autónoma de México. Una versión preliminar fue presentada en el seminario Identidades. Miradas desde la Antropología e Historia, del Instituto de Investigaciones Dr. José Luis Mora que dirige Rodrigo Laguarda y en el que recibí notables contribuciones.

** Agradezco las sugerencias de Gabriela Cano, María Dolores Lorenzo Ríos, Patricia Vega, Jorge Luis Peralta, Denisse Cejudo, Ernesto Seman y Juan Jacobo Henández; también la generosidad del archivo Camena de la Universidad Autónoma de la Ciudad de México.

cómo citar: Simonetto, P. (2020). La otra internacional. Prácticas globales y anclajes nacionales de la liberación homosexual en Argentina y México (1967-1984). Secuencia (107), e1697. DoI: https://doi. org/10.18234/secuencia.v0i107.1697 
Europa, América y Oceanía. Argumentamos que estos vínculos propusieron una temprana internacionalización de una identidad homosexual interpretada como radical que entró en tensión con la consolidación de la identidad gay, frente a la que terminó pereciendo. Además, destacamos cómo las vinculaciones con agrupamientos gays, trotskistas y feministas desempeñaron un papel central en la politización homosexual, y finalmente, cómo los efectos desiguales de los años setenta a lo largo del globo crearon tensiones por la definición de una identidad política.

Palabras clave: homosexualidad; historia global; sexualidad; México; Argentina.

Abstract: The purpose of this article is to study the practices, local and transnational networks, social translators and tensions surrounding the homosexual liberation movements of Argentina and Mexico. In order to achieve this objective, the author studies valuable archive material including publications from Europe, America and Oceania. We argue that this links proposed an early internationalization of the homosexual identity defined as radical that contrasted with the consolidation of the gay identity and that the first one tended to disappear. We also highlight the way links with gay, Trotskyist and feminist groups played a central role in homosexual politicization. Finally, we show how the unequal effects of the 70s throughout the world created tensions over the definition of a political identity.

Keywords: homosexuality; global history; sexuality; México; Argentina.

Recibido: 7 de enero de 2019 Aceptado: 9 de abril de 2019

Publicado: 12 de junio de 2020

$\mathrm{E}_{\text {(flHA), Fuad Zahra, envió una carta al Gay Liberation Front de Australia }}^{n}$ para denunciar las amenazas de exterminio de la extrema derecha peronista. Su misiva, publicada en la revista canadiense gay Body Politics, decía: "Cada movimiento de liberación homosexual está conectado con su propio país 
-nunca olvidamos el nuestro- pero sabemos que de alguna forma todos tenemos una tierra propia en abstracto, desde que se nos niega el derecho a amar y vivir en libertad necesitamos agarrarnos a algo místico para seguir viviendo [...] No pretendemos formar una internacional homosexual pero debemos permanecer en contacto." ${ }^{1}$

Esta carta es elocuente respecto a la consolidación de los movimientos de disidencia sexual radical. En América Latina emergieron grupos en Argentina, Brasil, Colombia, México, Perú y Venezuela entre 1967 y 1989 (Romero y Simonetto, 2019). Argentinos y mexicanos circularon cartas, libros y comunicados en búsqueda de solidaridad. También expresa una cultura política híbrida; como homosexual de izquierda, Fuad sufría sanciones estatales y sociales, por lo que debía desplegar un lenguaje que apelara a movimientos de otras latitudes y a la izquierda local que tenía un fuerte arraigo nacional y antiimperialista. La patria que pretendían liberar las izquierdas era un imaginario masculino en el que no cabían los muchachitos afeminados y pelilargos. La afirmación de Fuad es también la referencia de un sentir común por quienes formaban parte de una diáspora homosexual argentina, como afirmó el escritor Copi (2010): “¿La bandera de Canadá? Ni siquiera llevamos la bandera de la Tierra. Pertenecemos a todas las nacionalidades"; en su fundación de una utopía cosmopolita (Garrido, 2017).

El objetivo de este artículo es estudiar las prácticas, las redes locales y transnacionales, sus traductores sociales y las tensiones de los movimientos de liberación homosexual de Argentina (el flHA), y de México (el Frente de Liberación Homosexual Mexicano [flHM], Grupo Lambda; Frente Homosexual de Acción Revolucionaria [FHAR] y OiKABEth). A pesar del escaso contacto entre estos movimientos por su desfase temporal, en ambos países buscaron la solidaridad internacional yuxtaponiendo contactos con trotskistas, feministas, organismos de derechos humanos y gays como una renovación del imaginario político del internacionalismo. Comprensible en un periodo de transición en el que la emergencia del discurso planetario de los derechos humanos, en particular los aportes del activismo en América Latina para rechazar las violentas represiones ejercidas por las dictaduras, definió un ideario ligado a la "solidaridad" como una práctica que incluyó la denuncia y circulación de información (Moyn, 2012). La pregunta sobre cómo los activis-

1 "Letter from Argentina", Body Politic, núm. 17, enero-febrero de 1975, p. 8. Archives of Sexuality \& Gender. GALE (en adelante GALE). 
tas sin un contacto aparente desplegaron prácticas similares (Davis y Luna, 2013), permite identificar experiencias comunes: la coerción estatal y social, los complejos diálogos con las izquierdas y la mutación de sus identidades al calor de la globalización del modelo de vida gay (Altman, 2002).

Nuestra perspectiva acompaña a quienes cuestionaron la búsqueda de generalizaciones comparativas ajustadas a los Estados-nación modernos (Prado, 2013), una perspectiva que, anclada en la comparación y las conexiones, forma parte de una apuesta por entrever procesos que trascienden a las fronteras políticas (Drayton y Motadel, 2018). Así, el estudio de movimientos arraigados en ciudades con amplia influencia política, económica y cultural sobre Latinoamérica en el siglo xx y, en particular, en el activismo internacional, es una contribución central para el estudio de la politización de las identidades sexuales y sus vínculos con culturas políticas más amplias como la de las izquierdas.

Durante los años setenta del siglo $\mathrm{xx}$, las interconexiones previas entre disidentes sexuales plantearon una temprana internacionalización de una interpretación radical de la homosexualidad que entró en tensión con la globalización de la identidad gay (Altman, 2002; Laguarda, 2010). A pesar de ello, los intentos de estos grupos minoritarios no prosperaron y terminaron por ser marginados con la relativa integración con el cambio del siglo. Entiendo por gay una forma de sociabilidad y organización de las prácticas homoeróticas marcada por la flexibilización de las restricciones de los usos del espacio público, un sentimiento de pertenencia y la identificación mediante un consumo cosmopolita (Altman, 1996). La apropiación local de la identidad estuvo mediada por la conquista de libertades democráticas, el proceso de la crisis del sida y la visibilidad de una cultura emergente (Laguarda, 2010). En contraste, comprendo la homosexualidad como una identificación cambiante ligada a una experiencia histórica marcada por mayores restricciones estatales, familiares y comunitarias a su expresión pública y de la cual con posterioridad se diferenciaron diversas identidades sexuales.

Asimismo, en Argentina y México la política de liberación homosexual fue producto de la hibridación dialéctica entre las culturas locales, los activismos esparcidos con foco en Estados Unidos y Europa, junto con otras redes yuxtapuestas, como las desplegadas por el trotskismo y el movimiento de derechos humanos. Lejos de señalar estos vínculos como armoniosos, destaco que existieron tres tensiones clave: 1) la disputa de un imaginario de izquierda que ponderó una representación masculina y heterosexual; 2) la paradoja de 
los intentos los movimientos de liberación entre el deseo de pertenecer a la nación y el deseo de rechazar el discurso nacionalista (androcéntrico), y 3 ) la tensión entre el uso del vocablo "gay" y "homosexual" como expresión de modelos de sociabilidad y activismo político.

En las últimas dos décadas, los estudios sobre la politización homosexual en América Latina durante las décadas de los sesenta y setenta se ampliaron notoriamente (Ben e Insausti, 2017; Dehesa, 2010; Diez, 2011; Green, 2012; Laguarda, 2008; Mogrovejo, 2000; Romero y Simonetto, 2019; Simonetto, 2017; Vespucci, 2011), como también el estudio de la sociabilidad urbana (Green, 2001; Laguarda, 2007; Rodriguez Sanchéz, 2018; Simonetto, 2018). Se analizaron los vínculos transnacionales previos con el movimiento homófilo estadunidense (Gleibman, 2017; Macías-González, 2015; Rupp, 2011) y los proyectos de cosmopolitismos disidentes (Garrido, 2017; Loss, 2005). En México y en Argentina los años sesenta fueron estudiados como periodos de transformación de la cultura sexual urbana y se estudió a la nueva izquierda desde la perspectiva de género (Cosse, 2014; Felitti, 2018).

El llamado a abordar los años sesenta y setenta desde una perspectiva global promovió la indagación de los contextos y circuitos concretos de circulación, apropiación y producción de ideas y acciones (Marchesi, 2017; Pensado y Ochoa, 2018; Scheuzger, 2018). En este sentido, nuestra periodización responde a múltiples procesos. Por un lado, a las dinámicas propias de estos movimientos: en Argentina comenzó en 1967, se disolvió en 1976 frente a la dictadura militar y fue continuada su actividad por sus miembros exiliados; en México, los grupos se formaron inicialmente entre 1971 y 1978, luego tuvieron una actividad intensa hasta su disolución y transformación en 1984. A su vez, responde a los ecos de los años sesenta y setenta, los procesos de autoritarismo y democratización relativa que marcaron los ritmos de contracción o ampliación de la esfera política en ambos países.

Este artículo se organiza en tres apartados. Primero, presentamos una breve cronología de los movimientos políticos. Segundo, describimos las redes locales, transnacionales y los traductores sociales y políticos que desempeñaron un papel clave en esta trama, y, por último, analizamos las tensiones en los usos, apropiaciones y circulaciones del activismo homosexual radicalizado. 


\section{LA RADICALIZACIÓN DE LA HOMOSEXUALIDAD EN ARGENTINA Y MÉXICO}

En 1974, la dramaturga Nancy Cárdenas presentó la adaptación de la película Los chicos de la banda (Boys in the band) de Mart Crowley en el Teatro Insurgentes. El periódico Gay Sunshine: A Journal of Gay Liberation, referente de los movimientos en Estados Unidos, reprodujo una entrevista censurada por un editorialista mexicano. Ante la pregunta, "ipor qué eligió presentar este trabajo en México?", respondió: "Porque encuentro saludable y encantador mostrar que los jóvenes homosexuales son muy diferentes, sobre todo desde 1968, año en que comenzó la liberación homosexual."²

Su referencia a 1968 trascendió al movimiento estudiantil y a la masacre de Tlatelolco, en la que ella ya no participó como estudiante sino en su calidad de intelectual. ${ }^{3}$ Refería a un cúmulo de vivencias de una generación porosa en la que convergieron las transformaciones sociales y culturales de los largos años sesenta (Vaughan, 2014). En la década de 1950 se politizó en la juventud comunista de la Universidad Nacional Autónoma de México (UNAM) y participó de la protesta estudiantil de 1957 y 1958 y en el comunismo. Un viaje de estudios a Yale la puso en contacto con las premisas de la liberación gay estadunidenses. En 1971 promovió la creación del Frente de Liberación Homosexual Mexicano (FLHM) que, aunque funcionó clandestinamente y se disolvió en 1973, consolidó la incipiente politización radical de la identidad homosexual y lésbica (Monsiváis, 1994).

El FLHA fue un colectivo con el objetivo de aunar el ideario de la revolución sexual con la social. En 1967, Héctor Anabitarte, un afiliado del gremio del correo, fue sancionado, enviado al psiquiatra y, finalmente, expulsado del Partido Comunista por proponer un debate sobre la homosexualidad. Fundó el Grupo Nuestro Mundo (GNM) junto con un militante del sindicato de empleados estatales, un vendedor de máquinas de escribir y un joven vendedor de seguros, entre otros. En 1971, el GNM confluyó con el grupo Profesionales, fundado en 1970 en la Facultad de Filosofía y Letras de la Universidad de Buenos Aires (UBA), en el que militaba el escritor Néstor Perlongher, exmilitante

\footnotetext{
2 "Interview", Gay Sunshine: A Journal of Gay Liberation, invierno de 1975-1976, p. 7, en GALE.

Sobre el cuestionamiento al año 1968 como bisagra de la historia mexicana, véase el texto de Laguarda (2018).
} 
de un grupo trotskista, dando origen al FLHA. Al poco tiempo, este aglutinó a diez subgrupos que incluyeron a intelectuales y trabajadores marxistas, filoperonistas, cristianos con principios anticapitalistas, antipatriarcales y antiimperialistas. Aunque liderado por varones, algunas lesbianas conformaron el grupo SAFO, mientras otras se definirían sólo como mujeres al participar en la Unión Feminista Argentina (UfA). Luego de años de intensa actividad política, frente a la presión de grupos para estatales de la extrema derecha y frente el inminente golpe de Estado, el grupo se disolvió en 1976 y muchos de sus miembros se exiliaron.

Aunque alejados, los disidentes sexuales de Buenos Aires y de la Ciudad de México politizaron su identidad en un contexto de efervescencia política y represión. Ser homosexual en los setenta implicó coacciones sociales y policiales en ambas ciudades. En Argentina, desde la década de 1930, los códigos provinciales dotaron a oficiales de la policía de mecanismos para restringir la sociabilidad urbana de prostitutas, homosexuales, travestis, jóvenes y pobres (Simonetto, 2016). Igualmente, aunque no existió una ley de penalización específica, los mexicanos tuvieron que lidiar con la violencia policial (Laguarda, 2010; Rodríguez Sánchez, 2018). Por ejemplo, en 1978 un grupo de varones de Oaxaca denunció que en una fiesta privada en la que practicaban el transformismo fueron detenidos por policías, golpeados y fotografiados para luego publicar las fotos en la prensa. ${ }^{4}$

En ambos países reaccionaron contra estas políticas: en Argentina repartieron cartillas de seguridad ${ }^{5}$ y organizaron colectas para los detenidos; ${ }^{6}$ en México organizaron mítines frente a la delegación policial con apoyo de trotskistas del Partido Revolucionario de los Trabajadores (PRT), y, en 1979, los sindicatos de los trabajadores de la UNAM y la Universidad Autónoma Metropolitana (UAM) ${ }^{7}$ organizaron la Marcha por la dignidad homosexual, el primer antecedente de la marcha del orgullo en homenaje a Stonewall. ${ }^{8}$ Por el contrario, en Argentina, se organizó la primera Marcha del orgullo en 1992

${ }^{4}$ Testimonios de homosexuales de Oaxaca, 1978. Centro Académico de la Memoria de Nuestra América. Colegio de Humanidades y Ciencias Sociales. Universidad Autónoma de la Ciudad de México (CAmena-uacm), México (en adelante CAmena-uacm).

5 "Cartilla de seguridad", Somos, núm. 1, diciembre de 1973, pp. 10-12. Buenos Aires.

6 "Cada uno de nosotros tiene un amigo preso", Somos, núm. 4, agosto-septiembre de 1974, p. 1. Buenos Aires.

${ }^{7}$ Diario de México, 30 de septiembre de 1979.

${ }^{8}$ Comunicado, mayo de 1979, en CAmena-UACm. 
sin homenaje al levantamiento, y a partir de 1996 se convocó en noviembre en homenaje al grupo Nuestro Mundo. ${ }^{9}$

Tanto Cárdenas como Anabitarte -ambos comunistas- expresaron la ansiedad de capas minoritarias de la izquierda por encontrar nuevas agendas que desbordaran la referencia univoca al proletariado como sujeto político. Aunque el gobierno bolchevique de 1917 había eliminado del código penal la punición del sexo entre varones y permitió el trámite de convivencia, después el Estado soviético burocratizado de Stalin reinsertó las penas y afirmó a los partidos de la Tercera Internacional que la homosexualidad era la "máxima expresión de la decadencia burguesa contra natura” (Healey, 2002). En consecuencia, los comunistas de la región se distanciaron de identidades no heterosexuales y se resistieron a incluirlo en la agenda política, aunque para 1979 el Partido Comunista Mexicano (PCM) sí apoyó la demanda de alto a la represión policial. ${ }^{10}$

En México, la crisis del régimen posrevolucionario abrió un escenario en el que una nueva generación enfrentó el mandato patriarcal apelando al cosmopolitismo como contrasentido frente al nacionalismo (Zolov, 1999). La influencia de la revolución cubana y décadas de formación de un activismo estudiantil colaboraron en la formación de una nueva izquierda social. La masacre de 1968 profundizó la violencia autoritaria que abriría un escenario de violencia que comenzaría a morigerarse relativamente con las reformas de 1977 (Keller, 2015). ${ }^{11}$ En Argentina, se dio el "Cordobazo" en 1969, conjunto de movilizaciones que agruparon a trabajadores, estudiantes y sectores populares que socavó la legitimidad del régimen castrense que ejerció el poder desde 1966, visibilizó un nuevo escenario de conflictividad social y política: la extensión de una izquierda social formada con los procesos de resistencia a la proscripción peronista iniciados en 1955 (Scheider, 2006). Marcados por las resistencias a los autoritarismos y en contexto de la guerra fría, los grupos de disidentes sexuales apelaron y renovaron un lenguaje de izquierda con el que interpretaron su identidad generando tensiones.

${ }^{9}$ Cronología lgttbi. Comunidad Homosexual Argentina (s. f.). Recuperado de http:// www.cha.org.ar/cronologia-glttbi/ [consulta: 14 de noviembre de 2018].

${ }^{10}$ El Sol de México, 12 de diciembre de 1979.

${ }^{11}$ Reforma política con el que el Partido Revolucionario Institucional inició un camino de democratización relativa del régimen, aunque la apertura efectiva se llevaría décadas posteriores. 
En Argentina, finalizado el golpe en 1973, ante la reinserción del peronismo, el FLHA creció e intentó sumarse a las movilizaciones populares junto a las fracciones de izquierda del movimiento populista, pero su intento fue frustrado. En 1973 sus representantes se hicieron presentes en las manifestaciones de Ezeiza y en la de Plaza de Mayo para festejar el retorno al gobierno, valiéndose de consignas nombradas en la marcha peronista como "para que en el pueblo reine el amor y la igualdad". Pero un sector de la derecha peronista empapeló la ciudad con la frase: "El ERP, los homosexuales y drogadictos", por lo que la izquierda rechazaría a los homosexuales con el cántico: "No somos putos, tampoco faloperos, somos soldados de Evita y Montoneros".

En 1974 se formó el grupo SExPoL, un espacio de contención afectiva, acción política y producción teórica que promovía los cruces entre el marxismo y el psicoanálisis. Ese mismo año, la UnAm recibió a Kate Millet y a Susan Sontag, dos relevantes figuras del movimiento de liberación feminista en Estados Unidos que colaboraron a reformar estos discursos en México. ${ }^{12}$ En Argentina, el FLHA, algunas feministas y trotskistas conformaron el Grupo de Política Sexual. Al igual que los mexicanos, estudiaron y produjeron documentos en los que fundamentaron las necesidades de una revolución sexual.

La coincidencia de nombres remitía a la inscripción de estos movimientos en las teorías de la liberación del deseo, un pensamiento híbrido entre el psicoanálisis freudiano y el marxismo que suponía que la revolución no sólo debía liberar al proletario de la venta forzosa de su fuerza de trabajo, sino también de la sujeción de su deseo y su cuerpo sexuado. La familia se tornó blanco de críticas al señalársela como máquina de producción de sujetos para su inserción en el mercado capitalista (Vespucci, 2011). Con foco en la circulación de ideas, además de escribir panfletos, manifiestos y declaraciones, los activistas produjeron publicaciones que constituyeron la primera saga de revistas abiertamente homosexuales de la región. El FLHA publicó Somos entre 1973 y 1976, mientras que los grupos mexicanos publicaron los Cuadernos de Política Sexual, Nuestro Cuerpo y Nuestro Ambiente.

En 1975, Luis González de Alba -testigo de la masacre de Tlatelolcopublicó, junto con Carlos Monsiváis, Elena Poniatowska, Nancy Cárdenas, y otra decena de intelectuales, una declaración en la revista Siempre! cuestio-

12 C. Lugo, Semblanza de Alaíde Foppa. Recuperado de http://www.jornada.com. $\mathrm{mx} / 2000 / 01 / 03 /$ alaide-resena.htm 
nando la represión policial a homosexuales. ${ }^{13}$ En 1978, en la conmemoración del movimiento de 1968, distintos grupos se manifestaron por primera vez como grupos homosexuales, ${ }^{14} \mathrm{y}$ recibieron un recibimiento menos hostil de la izquierda partidaria que sus pares argentinos (Dehesa, 2010). En ese año se formó el Frente Homosexual de Acción Revolucionaria (FHAR) liderado principalmente por varones, el grupo Lambda de Liberación Homosexual -con mayor participación lesbiana-y el grupo OІквETH, ${ }^{15}$ una derivación del temprano grupo Lesbos, que aunque coordinaron con el FHAR definieron un camino autónomo.

Por su carácter abierto y por la habilitación a la doble militancia, las feministas argentinas y mexicanas fueron un nexo con el trotskismo local, el Partido Socialista de los Trabajadores (Argentina) y el Partido Revolucionario de los Trabajadores (México). Los trotskistas de ambos países celebraron que la cuarta internacional con sede en Francia (secretariado unificado), incluiyera la liberación homosexual en su programa,${ }^{16}$ Sin embargo, estos movimientos siguieron contemplando la "opresión sexual" como un elemento subordinado a las relaciones capitalistas de clase (Tresbisacce y Mangiantini, 2015).

Mientras el fHAR priorizó la confluencia con trotskistas, Lambda anunció entre sus objetivos la confluencia con el feminismo por una "liberación sexual general", ${ }^{17}$ lo que expresó la unión en la noción misma de liberación como una metáfora entre la politización del cuerpo y los procesos de descolonización, una lucha por la búsqueda de una autonomía y libertad plena (Barba, 2017). El feminismo mexicano resurgió en los años sesenta inspiradas en la "segunda ola", compartió con los movimientos de liberación homosexual una fuerte crítica al sistema social y a las desigualdades de género. En este sentido, tuvo estrechos puntos de contacto con las disidencias sexuales. Entre ellos se destaca la organización de un contracongreso en 1975 como respuesta al Congreso Mundial por los Derechos de las Mujeres de la Organización de las Naciones Unidas (ONU), así como también, en 1979, la construcción del Fren-

13 Siempre!, julio de 1975.

${ }^{14}$ El Sol de México, 27 de julio de 1978.

${ }^{15}$ En maya significa, Movimiento de Mujeres Guerreras que Abren Camino y Esparcen Flores.

${ }_{16}$ "Manifiesto del Comité Central de la Liga Comunista" (sección francesa de la IV Internacional, enero de 1972) [fragmento], Somos, núm. 3, mayo de 1974, p. 39, Buenos Aires.

${ }^{17}$ Unomásuno, 27 de diciembre de 1979. 
te Nacional de Liberación y los Derechos de la Mujer, en el que convergieron el FHAR, sindicatos, el trotskismo y el feminismo (Cano, 1996).

Los grupos mexicanos tuvieron un alcancé territorial mayor que los argentinos. El flHA se concentró en la ciudad de Buenos Aires y mantuvo contacto con círculos de Tucumán, Mendoza y Mar del Plata (Acevedo, 1985, p. 250). El fHAR organizó delegaciones en Oaxaca, Aguascalientes, Veracruz y Puebla. ${ }^{18}$ A pesar de que el FHAR fue liderado por varones, en contraste con los argentinos, también promovieron la visibilidad de identidades como las vestidas, travestis y lesbianas.

En 1975, El Caudillo, expresión pública de la Alianza Anticomunista Argentina (AAA) incitó a acabar con los homosexuales. Proponía "crear brigadas callejeras que salgan a recorrer los barrios para que den caza a estos sujetos vestidos como mujeres, hablando como mujeres, pensando como mujeres. Cortarles el pelo en la calle o raparlos y dejarlos atados en los árboles con leyendas didácticas.” El FLH respondió públicamente con un volante titulado El fascismo nos amenaza (1975). Anunció a sus "hermanos y hermanas que la hora de unión total y sin claudicaciones ha llegado: los homosexuales argentinos debemos unirnos sin vacilaciones para defender nuestro derecho a la libertad y a la vida, y enfrentar a nuestro enemigo común: el fascismo [...] si deponemos nuestros miedos personales en beneficio de todos, podremos vencer y conquistar la dignidad humana que se nos niega" ${ }^{19}$ La violencia política en ascenso y el golpe militar que tomo el poder en 1976 marcaron el final de su organización.

En 1981, el FHAR decidió disolverse por diferencias internas y al evaluar que no había formado cuadros suficientes. ${ }^{20}$ Un dibujo perdido entre sus papeles expresa en parte el caos administrativo del movimiento, los múltiples límites que dificultaron su acción: la presión familiar, el escaso financiamiento, los intereses personales, las desconexiones entre sus miembros y la interconexión entre el lenguaje de su "dirección". Los personajes bailando en el gueto señalan las dificultades de vinculación entre los núcleos políticos y los que esperaban fueran su base política (véase imagen 1). Algo similar fue destacado por Néstor Perlongher (2014) cuando una vez exiliado en Brasil

18 FHAR informa, núm. 1, 1979, en CAMENA-UACM.

19 FLHA, El fascismo nos amenaza, 1975. Archivo Comunidad Homosexual Argentina (en adelante ACHA).

${ }^{20}$ FHAR, “Comunicado de disolución”, 1981, en CAMENA-UACM. 
ESTRUCTURA ACTUAL DEL FHAR

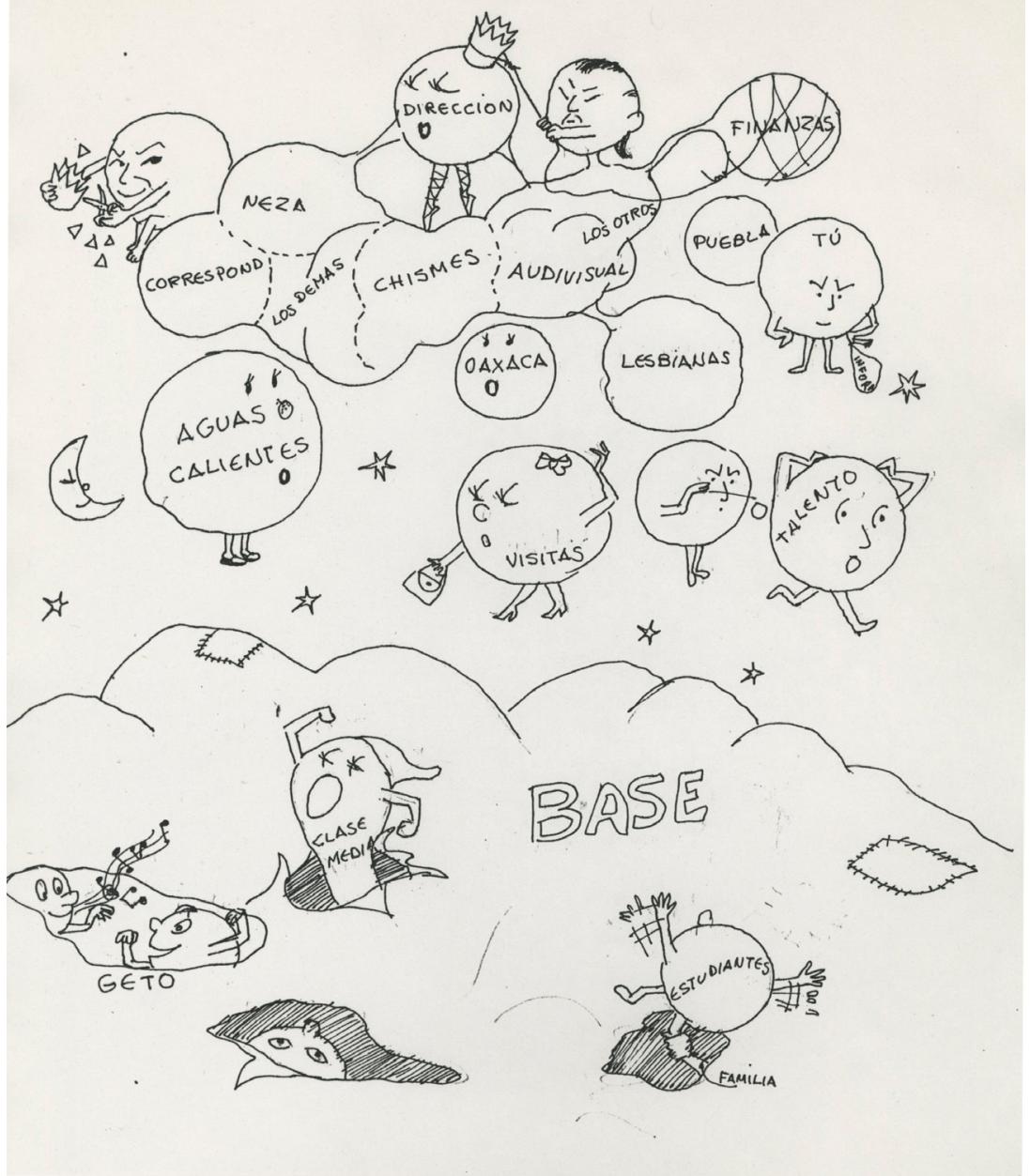

Imagen 1. Archivo FHAR, s. f., en CAMENA-UACM. 
definió la experiencia del fLHA como un "fracaso". La asistencia a un bar de homosexuales bonaerense y sus intentos de aclamar demandas políticas por el micrófono era desoído para quienes lejos de buscar la revolución esperaban una integración civil que les permitiera disfrutar su vida, lo cual llegaría décadas más tarde (Simonetto, 2017). En México algunos activistas se integraron al Movimiento de Liberación Homosexual, lo que marcó un cambio progresivo de la lógica de las movilizaciones que tendería a integrarse a la acción por la reivindicación de los derechos civiles. El sismo año de 1985 marcaría un punto clave, el viraje definitivo hacia la emergencia de la identidad gay y las políticas de acción civil (Laguarda, 2010).

\section{CONTEXTOS GLOBALES, REDES TRANSNACIONALES, ESPACIOS Y TRADUCTORES}

En 1973, el FLHA recibió una epístola del National Gay Task Force que hacía explicita su intención de "trabajar con todas las organizaciones posibles por la liberación homosexual nacional e internacional" ${ }^{21} \mathrm{El}$ FLHA utilizó los contactos con el agrupamiento estadunidense, ofreció su casilla postal para recibir el correo para evitar exponerse a ataques. ${ }^{22}$ En ese mismo año fueron presentados en Europa por el Fronte Unitario Omosessuale Rivoluzionario Italiano (FUORI) ligado al Partido Radical (Barilli, 1999). El periódico italiano reprodujo una reseña de la actividad del FLHA y una entrevista a sus referentes de la revista sensacionalista $A s i ́$.

Los movimientos buscaron la solidaridad internacional construyendo redes que superaran las fronteras nacionales. A los argentinos les permitió difundir la represión y las amenazas de las que eran objeto, como también continuar campañas contra la dictadura una vez exiliados. Los mexicanos organizaron mítines para protestar en las embajadas de Argelia, Brasil y Canadá contra la represión a los homosexuales,${ }^{24}$ hicieron circular comunicados y buscaron espacios comunes de intercambio político.

${ }^{21}$ Evan Stein, "Carta de la National Gay Task Force (Nueva York, 14 de diciembre)", Somos, núm. 2, febrero de 1974, p. 32, Buenos Aires.

22 "A dónde se envía", Somos, núm. 3, mayo de 1974, p. 40, Buenos Aires.

${ }^{23}$ Frente de Liberación Homosexual de la Argentina, Fuori!, núm. 11, 1973, p. 8, en GALE.

24 Nuestro Cuerpo, núm. 1, abril de 1979, p. 1, México. 
La formación social, política y cultural de estos grupos estuvo marcada por diversas dimensiones transnacionales: contextos, redes, espacios y traductores. En contraste con Argentina en donde la censura impulsada por los gobiernos militares restringió el acceso a textos, en la ciudad de México, desde la década de 1950, se ofrecieron algunas de las principales revistas homófilas (Macías-González, 2015). Mientras Nancy Cárdenas y Carlos Monsiváis celebraron la influencia de la revuelta de Stonewall o los grupos británicos (Monsiváis, 1994), los argentinos no hicieron referencia alguna a este acto en sus materiales. El grupo Nuestro Mundo fue particularmente influido por el texto de Huey Newton's: "A Letter from Huey to the Revolutionary Brothers and Sisters about the Women's Liberation and Gay Liberation Movements", publicado por los Black Panthers en 1970. El texto influyó en la interpretación sobre la opresión social a lesbianas y homosexuales, asimismo, la crítica sobre el racismo resonó en las crecientes demandas de liberación nacional que identificaron a Estados Unidos como un obstáculo para un cambio social profundo (Ben e Insausti, 2017, p. 32).

Las ideas de la liberación homosexual circularon en libros, cartas y documentos. Tanto los argentinos como los mexicanos leyeron con atención Eros y civilización, de Herbert Marcuse (1972), y Sexual politics de Kate Millett (1972). A mediados de la década de 1970 la consolidación de las culturas feministas y de liberación homosexual en México trajo aparejado una prolífica edición de libros que por medio de viajes y correspondencias llegaron a la biblioteca de los miembros del FHAR. ${ }^{25}$ Juan Jacobo Fernández se sintió particularmente marcado por el libro Elementos de una crítica homosexual, de Mario Mieli (1979), fundador del movimiento homosexual en Italia, introducido al mundo hispano por traductores españoles, y Homosexualidad y sociedad repre-

${ }^{25} 25$ to 6 Baking \& Trucking Society (1972); Altman (1996); Aubrey (1980); Bell (1971); Bell, Weinberg, Indiana University, \& Institute for Sex Research (1979); Boggan Haft, Lister, Rupp y Stoddard (1983); Bosch y Frente Homosexual de Acción Revolucionaria (1979); Brohm, Brückner, Dahmer, Fernbach, Gartheret, Jervis (1973); Cassidy y Stewart-Park (1977); Duflot (1971); Eck y Mok (1969); Foster y Murray (1972); Garskof (1971); Gay Academic Union, New York Chapter y Scholarship Committee (1985); Grier y Reid (1976); Guerin, Daniel (1969); Humphreys (1972); In the spirit of Stonewall (1979); Jay y Young (1992); Leyland (1979); Lizarraga (1978); Masters (1964); Masters y Johnson (1982); McCubbin (1979); Milligan (1973); Mitchell, Asta, y Calamus Books (1988); Murphy (1971); Nichols (1980); Nicolas (1982); Parker y Parker (1977); Radius (1970); Reich (1972); Richmond y Noguera (1979); Rowse y Liaras Muls (1988); Simons (1965); Smith (1977); Sylvestre (1979); Ussel (1974); Valdiosera (1973); Weeks, (1991); Weeks y Rowbotham (1978); Wolf (1980); Young (1981). 
siva de Guy Hocquenghem (1974), líder de los homosexuales radicalizados en Francia, traducido en Buenos Aires.

La década de 1970 marcó una expansión de los circuitos globales de comunicación entre disidentes sexuales (Hilderbrand, 2013) que trascendió a los grupos políticos, por ejemplo, la guía de viaje gay Spartacus ofrecía desde 1970 información actualizada que recibía de sus corresponsales en español, francés e inglés y alertaba sobre las políticas restrictivas, organizaciones políticas, bares y zonas de ligue. ${ }^{26}$

La estética de las manifestaciones públicas se nutrió de la circulación de estéticas políticas. En una de las fotografías que el FLHA decidió publicar para presentarla al público se cubrieron el rostro con el término "PODER homoseXuAL" en una referencia múltiple al Black Power de las panteras negras, Gay Power de los movimientos estadunidense y de las guerrillas locales. ${ }^{27}$ Aunque algunos de ellos dieron sus nombres en entrevistas, aparecer frente a cámara podría tener un costo. Era una metáfora potente en la que, por un lado, se marcaba el carácter discreto que cercenaba su acción política y sus vidas, pero también revelaba que incluso en esa condición, mostrarse asociados a la homosexualidad como una posición de poder, era una forma de agenciar positivamente su identidad en los mismos medios que los fustigaban. Para los integrantes del FLHA, "aparecer" en público conllevaba la pérdida del lazo familiar, el trabajo o la violencia física. Otro activista, Sergio Pérez Álvarez, sostuvo que cuando eran fotografiados en una manifestación debía ocultarse por miedo a que la imagen le costase su trabajo como director de un jardín de niños. ${ }^{28}$ Los que pudieron mostrarse en público como homosexuales apelaron a la misma imagen desafiante que los jóvenes de izquierda, y en las manifestaciones retomaron consignas de la marcha peronista ${ }^{29}$ (véase imagen 2).

Las fotografías de la Marcha por la dignidad homosexual muestran mayor porosidad entre las clásicas figuras de la movilización pública que caracterizó a la izquierda y las consignas del Gay Pride que ese mismo año tomaba las principales ciudades de Estados Unidos. En este sentido, la confección de pancartas en las que convivía el término local homosexual y con el anglicismo gay expresan mayor fluidez con los movimientos del norte, pero también la

\footnotetext{
26 Spartacus International Gay Guide, 1970, Alemania, en CAMENA-UACM.

${ }^{27}$ Así, núm. 891, julio de 1973, Buenos Aires.

28 Entrevista a Sergio Pérez Álvarez, 10 de enero de 2014.

${ }^{29}$ Así, núm. 891, julio de 1973, Buenos Aires.
} 


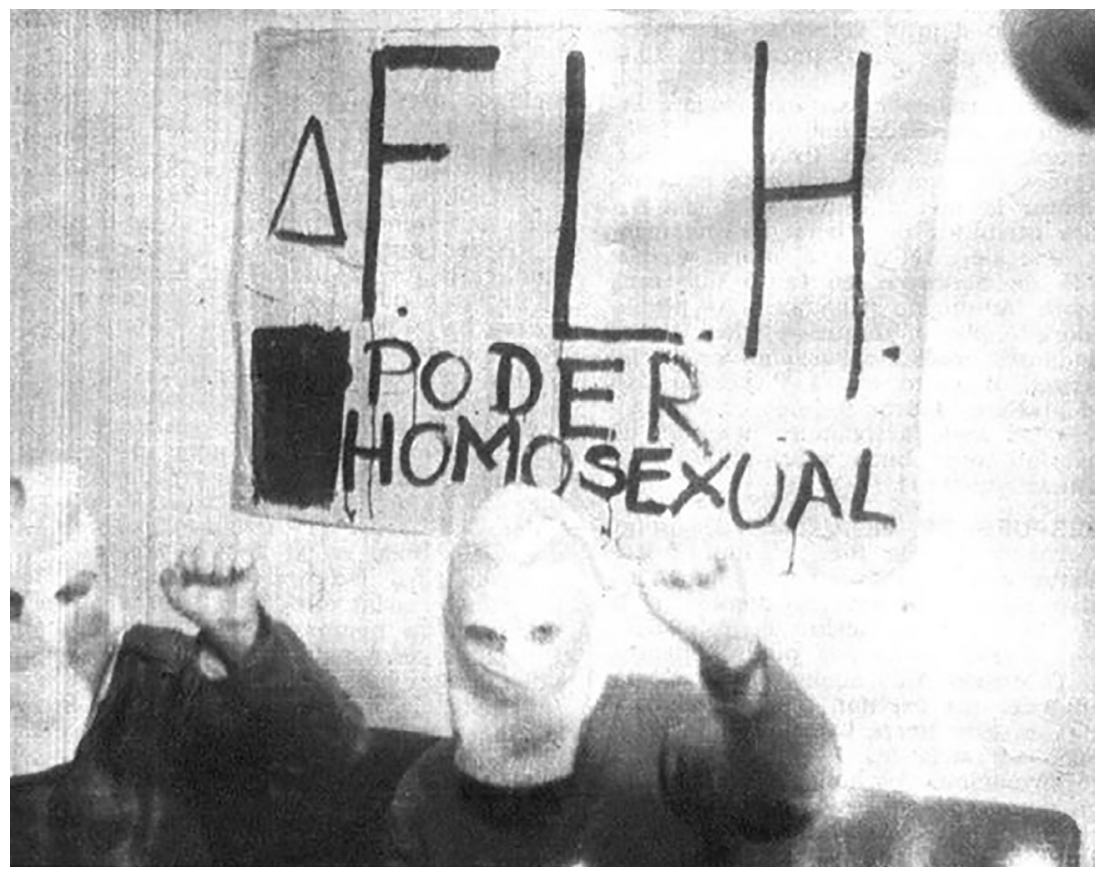

Imagen 2. Así, núm. 891, julio de 1973, Buenos Aires.

incipiente extensión del modelo de identidad irradiado por las capitales occidentales (véase imagen 3).

La visibilidad restringida en Argentina y notoria en México de homosexuales politizados generó reacciones locales. La extrema derecha argentina ligada al Estado atacó al FLHA por considerarlos afeminados y remarcó sus demandas como importaciones foráneas contrarias a la identidad nacional. La organización de ultraderecha católica Tacuara afirmaba que la "homosexualidad y la coca cola" eran inventos del imperio, ${ }^{30}$ mientras que otros agrupamientos los acusaron de ser agentes de la CiA contrarios al gobierno de Perón. ${ }^{31}$ En México, la Unión Nacional de Padres de Familia solicitó al gobierno que se interrumpiera las actividades de grupos homosexuales en la Universidad Autóno-

30 Tacuara, núm. 11, agosto de 1969, Buenos Aires.

31 "Letter from Argentina", Gay Sunshine: A Journal of Gay Liberation, invierno de 19751976, p. 12. 


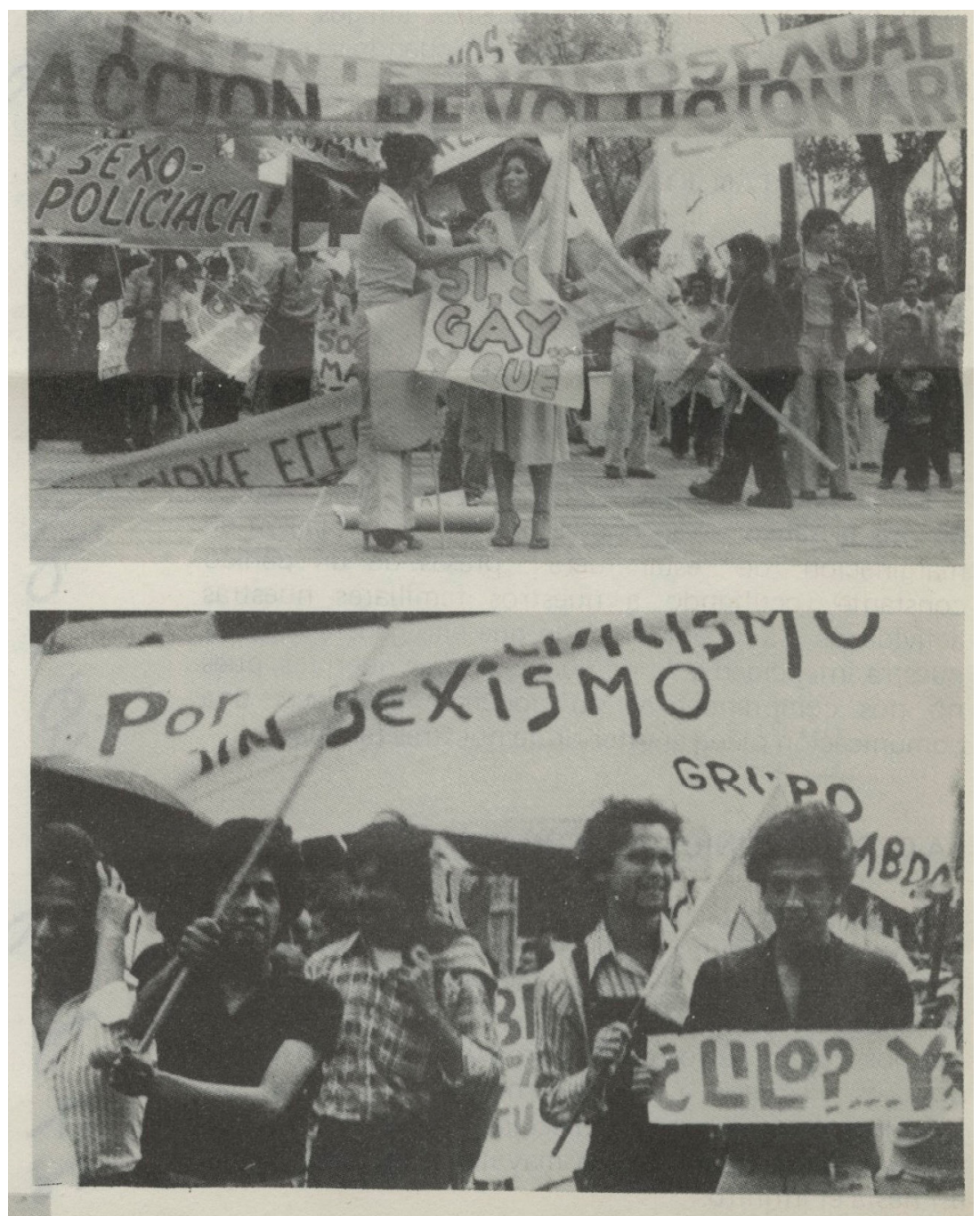

Imagen 3. Marcha por la dignidad homosexual, México, 1979, en CAMENA-UACM. 
ma Benito Juárez de Oaxaca. ${ }^{32}$ Algunos periodistas afirmaron que el activismo homosexual formaba parte de un plan de importación de "problemas del extranjero" y eran intentos de "los maricas y las lesbianas de armar un partido". ${ }^{33}$

Desde sus países de origen o en el exilio, los activistas intervinieron en redes transnacionales. La referencia de Fuad a una "Internacional homosexual", ${ }^{34}$ es elocuente de los mecanismos y lenguajes yuxtapuestos en un diálogo tenso con movimientos de liberación homosexual con una izquierda trotskista aferrada a la idea de reconstruir una internacional de partidos obreros y los movimientos por derechos humanos. No había un objetivo común global antisistémico, sino una renovación del ideario de la solidaridad como un factor elemental de la acción política.

La circulación de comunicados, noticias, entrevistas y cartas se expresaron en universos extensos de revistas de Europa, Oceanía y América entre los que se incluyó la prensa feminista, trotskista, de disidencia sexual o de interés general. Pero a pesar de la profusa actividad en otros países, por la asíncronía temporal, el vínculo entre agrupamientos de México y Argentina fue escaso e indirecto. Los mexicanos consiguieron el manifiesto Sexo y Revolución del FLHA por medio de los trotskistas de San Francisco y buscaron una traducción al medio local a través de sus publicaciones. ${ }^{35}$ Ambos intentaron liderar un proyecto de articulación latinoamericano por medio de la Coalición Homosexual Latinoamericana con sede en Nueva York. En 1975, el FlHA anunció que le propuso a la Comunidad de Orgullo Gay de Puerto Rico y al Frente de Liberación Homosexual de México (en aquel momento ya disuelto) establecer una coordinadora homosexual latinoamericana. ${ }^{36}$ En 1978, Juan Jacobo Hernández se contactó con los mismos grupos que el FLHA. Sin embargo, su esperanza de establecer una coordinación con los activistas de Puerto Rico y Costa Rica fracasó, ya que las agrupaciones de estos países se habían disuelto. ${ }^{37}$

32 "Campaña permanente en defensa de nuestros hijos", panfleto, Oaxaca, 26 de septiembre de 1978, en CAMENA-UACM.

33 Oaxaca Noticias, 11 de marzo de 1981.

34 "Letter from Argentina", Body Politic, núm. 17, enero-febrero de 1975, p. 8, en GALE.

35 Entrevista a Juan Jacobo Hernández, 6 de noviembre de 2018.

36 "Informaciones del exterior", Somos, núm. 8, enero de 1976, p. 2, Buenos Aires.

37 FHAR, boletín interno, núm. 2, 1979, en CAMENA-UACM. 
Desde Buenos Aires, el fLHA envió comunicados a quince publicaciones gays, ${ }^{38}$ dos feministas ${ }^{39} \mathrm{y}$ como exiliados a otras $17{ }^{40}$ Inscritos en un periodo de mayor proliferación de movimientos y publicaciones, a finales de la década de 1970 y comienzos de la de 1980, miembros del FHAR, Lambda у OІKABETH intervinieron en cuatro publicaciones trotskistas ${ }^{41}$ en 17 periódicos feministas, ${ }^{42} y$ en 23 periódicos gays. ${ }^{43}$ Formaban parte de un universo de publicaciones baratas que emergieron en las ciudades occidentales como constructor de una sociabilidad homosexual (D'Emilio, 2014, p. 86). Periódicos de Australia, Brasil, Colombia, Canadá, Escocia, Italia, Francia, Estados Unidos, Venezuela y Nueva Zelanda resultaron espacios de circulación común. Tanto el FLHA y el FHAR reprodujeron comunicados de grupos de chicanos en Estados Unidos, en particular los argentinos lo hicieron como parte

${ }^{38}$ Arcadie (Francia), Body Politics, Camp Ink (Sydney, Australia), Come Out (Village Station, Estados Unidos), Digital Reporter (San Francisco, Estados Unidos), Fuori (Italia), Gay Liberation Press (Sydney, Australia), Gay Liberator (Estados Unidos), Gay Marxist (Lancaster, Inglaterra); Gay News (Inglaterra); Gay Scene (New York, Estados Unidos); Gay Task Force (Estados Unidos), Gay Sunshine: A Journal of Gay Liberation (Estados Unidos), GLP! (Chicago, Estados Unidos) y Pittsburgh Gay News (Estados Unidos).

${ }_{39}$ Big Mama Rag (Denver, Estados Unidos) y The Lesbian Inciter (Estados Unidos).

40 Arcadie (Francia), Come Out (Estados Unidos), Campaign (Australia), Entendido (Venezuela), El Otro (Colombia), Gay Hosta (España), Gay Scotland (Glasgow, Scocia), International Gay Association Bulletin (Bruselas, Bélgica), Gaysweek (Estados Unidos), Lambda (Barcelona, España), Mundo Gai (España), Nós (Portugal), Out! New Zealand's Alternative, Lifestyle (Nueva Zelanda), Limpao Esquina (Brasil), Pink Triangle (Wellington, Nueva Zelanda), y Revolt (Estocolmo, Suecia).

${ }^{41}$ Mieli (México), Torch (Jamaica), Torch (Nueva York, Estados Unidos) y Workers World (Estados Unidos).

${ }^{42}$ Big Mamma Rag (Denver, Estados Unidos), Ciao! (Nueva York, Estados Unidos), Hera (Filadelfia, Estados Unidos), Le Berdache (Montreal, Canadá), Le Petit Berdoche (Canadá), Majority Report (Berkeley, Estados Unidos), Masques (Francia), News Direction of Women (1972-1998), Out and About (Seattle, Estados Unidos), Pandora (Seatle, Estados Unidos), Plexus (San Francisco, Estados Unidos), SAPHO (Estados Unidos), Sister (California, Estados Unidos), The Lesbian Inciter (Minneapolis, Estados Unidos), The Womens New Journal (San Rafael, Estados Unidos), Update (San Diego, CA., Estados Unidos), Upstream (Ottawa, Canadá).

${ }^{43}$ Lambda (Chile), Lambda (Washington, Estados Unidos), Lambda (Indonesia), Gay News (Inglaterra), Update (San Diego, Estados Unidos), GPU News (Milwaukee, Estados Unidos), Philadelphia Gay News (Filadelfia, Estados Unidos), Sonoma County Lesbian and Gay Alliance (Santa Rosa, Estados Unidos), Limpao Esquina (Brasil), International Gay Association (Bélgica), Gay Sunshine (Estados Unidos), Gay News (Estados Unidos), Gay Task Force (Nueva York, Estados Unidos), Gay Comunity News (Estados Unidos), Movimiento de Liberación Homosexual (Costa Rica), Tomonokai (Japón), Gay Left (Inglaterra), Gaysweek (Nueva York, Estados Unidos), Moja Gay \& Black (Nueva York, Estados Unidos), After Stonewall (Canadá), Pink Triangle (Nueva Zelanda) y Gaysweek (Nueva York, Estados Unidos), e International Gay Asociation (Escocia). 
de su rechazo al imperialismo, como expresó la portada del quinto número de su revista Somos en la que una pequeña mariposa se enfrentaba a un águila de la CIA. ${ }^{44}$ En 1979, los grupos mexicanos participaron de un bloque de gays latinos en una manifestación en Washington. ${ }^{45}$ Como exiliados, los argentinos solicitaron a activistas de todo el mundo que enviaran cartas a los directores de las cárceles argentinas para rogar por su liberación. ${ }^{46}$

Los diálogos se establecieron en torno a temáticas como los mítines argentinos contra la represión del dictador Pinochet contra las disidencias sexuales en Chile, la primera marcha por la "dignidad homosexual" en México en 1979, las amenazas de la extrema derecha al FLHA, y las denuncias contra el golpe militar de 1976. El FHAR y el FLHA participaron de congresos internacionales en los que se promulgaban estrategias por la lucha de los derechos homosexuales, por ejemplo, el FLHA leyó un documento en el congreso del Partido Radical Italiano en 1975 y en el Gay Congress Rights celebrado en Edimburgo ${ }^{47}$ Los mexicanos tuvieron también instancias importantes como la Conferencia Internacional de la Mujer celebrada en la capital mexicana en 1975, en la que Nancy Cárdenas coordinó una acción común con lesbianas estadunidenses. Además, activistas latinoamericanos, embarcados en una perspectiva con un anclaje más institucional de Brasil, México, Jamaica, Venezuela y Puerto Rico, participaron en la formación de la International Gay Association (IGA) (Dehesa, 2010).

Los procesos de circulación e interconexión de la política homosexual radical se constituyeron gracias a los traductores sociales, políticos y culturales que establecieron puntos comunes, transportaron materiales, relataron experiencias y reelaboraron sus propias prácticas al calor de la movilidad (Rojas, 2016). Néstor Perlonguer (1949-1992), poeta, sociólogo y líder del FLHA, se exilió en Campiñas (San Pablo, Brasil) tras el golpe de Estado en Argentina en 1976 para hacer una maestría en Antropología Social durante la cual escribió su libro sobre la prostitución masculina (Perlongher, 1999). Estando ahí se consideró un "exiliado sexual" y entró en contacto con los miembros de los grupos brasileños Somos y Limpao Esquina, los cuales asumieron ese mote en homenaje al grupo argentino. También en el exilio transformó sus nocio-

${ }^{44}$ Sección: Correspondencia del Exterior (carta de Greater Liberated Chicanos, 15 de mayo de 1974). Somos, núm. 4, agosto-septiembre de 1974, pp. 12-14, Buenos Aires.

45 "Introducción", Lambda, 1979.

46 "Repressao Gay Na Argentina”, Jornal Do Gay, núm. 4, 1979, en GALE.

47 "Informaciones del exterior", Somos, núm. 8, enero de 1976, p. 2, Buenos Aires. 
nes plenamente ligadas al marxismo, como su recepción de los textos de Gilles Deleuze y Félix Guatari (Garrido, 2017; Paniagua García, 2017; Palmeiro, 2011). La circulación de sus textos y libros, alojados en la biblioteca del FHAR mexicano, funcionaron también como vehículos de traducción. ${ }^{48}$

Néstor Latrónico era un joven dactilógrafo que en 1970 huyó de las represiones moralistas de la dictadura de Juan Carlos Onganía y se mudó a Nueva York. Allí se involucró con los grupos de concientización del Gay Liberation Front y grupos latinos, en 1973 regresó a Argentina para colaborar con el FLHA. Estableció vínculos, participó en las reuniones del Grupo de Política Sexual, colaboró en la traducción de textos feministas censurados en Argentina e importados por la cineasta María Luisa Bemberg, y con cartas y documentos con agrupamientos anglosajones. ${ }^{49}$ Como fundador del Third World Gay Revolution, un grupo de latinos, publicó poemas y difundió los problemas que aquejaban a los homosexuales en América Latina. ${ }^{50}$

Héctor Anabitarte, fundador del Grupo Nuestro Mundo en 1967, se exilió en España en donde colaboró con las múltiples publicaciones que promulgaron los derechos de la comunidad gay. Respecto a su actividad en Buenos Aires, fue responsable de mezclar su herencia como militante comunista con las ideas de los Black Panters (Ben e Insausti, 2017).

Otros personajes como el periodista Fuad Zahra (1942-2015), del FLHA, colaboró también como vínculo con los miembros de la UFA, con la reproducción de sus documentos, y la organización de actividades conjuntas con la Coordinadora contra la Prohibición de Ventas de Anticonceptivos, con la que se opusieron a la propuesta puritana de Isabelita de Perón de vetar tales tecnologías. ${ }^{51}$ Escribió cartas a grupos en Nueva Zelanda, Canadá y Australia para difundir las actividades locales y denunciar la violencia del Estado argentino. ${ }^{52}$

Manuel Puig (1932-1990), reconocido escritor y colaborador del FLHA, fue un prodigioso divulgador de las ideas de la liberación homosexual. Su libro El beso de la mujer araña condensó en su figura el diálogo entre un militante de izquierda y un homosexual despolitizado en la cárcel y se hizo eco así de una figura alegórica de la época. Su libro fue prohibido en Argentina (así como el conjunto de su obra desde 1974) pero se publicó en 1976 en Barcelona,

\footnotetext{
48 Biblioteca Nancy Cárdenas, en CAMENA-UACM.

49 Entrevista a Néstor Latrónico, 10 de diciembre de 2013.

50 "Poetry", Come Out, vol. 1, núml 5, septiembre-octubre de 1970, p. 14, en GALE.

${ }^{51}$ FLH. Coordinadora contra la prohibición de venta de anticonceptivos, s. f., en ACHA.

52 "Letter from Argentina", Body Politic, núm. 17, enero-febrero de 1975, p. 8, en GALE.
} 
aunque lo terminó de escribir en México. Su obra circuló de forma clandestina en Buenos Aires y en México tuvo un gran éxito, además fue traducido a numerosos idiomas. En las notas a pie difundió algunas de las ideas elaboradas por el FLHA sobre la liberación homosexual. El libro tuvo un impacto enorme en las publicaciones homosexuales de Brasil, México, Alemania, Canadá, Holanda, Suiza, Suecia, Francia, República Checa, Italia, Dinamarca, Austria, España y Nueva Zelanda. ${ }^{53}$

Nancy Cárdenas (1934-1994) fue una figura clave en el proceso de traducción entre México y Estados Unidos. Su visita a la Universidad de Yale la puso en diálogo con las ideas de la liberación gay. Una vez formado el FLHM, le informó de sus actividades a Carlos Monsiváis quien estaba en Londres, y fue él quien le retribuyó sus opiniones sobre el movimiento británico (Monsiváis, 1994). Como dramaturga desplegó la temática homosexual, una polémica constante con aquellos representantes de los medios que estigmatizaban la vida sexual disidente en la Ciudad de México. ${ }^{54}$ En 1973 anunció su homosexualidad públicamente en el programa 24 Horas, con Jacobo Zabludovsky. En 1975 formó parte del grupo de lesbianas que, en coordinación con las feministas estadunidenses que llegaron a la Conferencia Internacional de la Mujer, hicieron un contraencuentro. Definida por sus pares del norte como una One-Women-Movement, fue presentada como una heroína por sus elocuentes presentaciones y rechazada por un grupo de mujeres católicas que la consideraban representante, a quienes acusó de estar pagadas por el jefe de la policía local. Aunque con tensiones, la obra y la figura de Cárdenas cruzaron las fronteras y se transformó en un nodo clave de la interconexión entre los mundos del feminismo y el movimiento homosexual local y global..$^{55}$

${ }^{53}$ Interview mit Manuel Puig, Berliner Schwulen Zeitung (Berlín, Alemania), abril-mayo de 1980, núm. 21; Le aaiser de la femmearaignée, Le Berdache (Montreal, Canadá), diciembre de 1979-enero de 1980, núm. 6, p. 40; Manuel Puig, Homologie (Ámsterdam, Países Bajos), noviembre-diciembre de 1983, núm. 6, p. 27; Il Bacio Dell'argentino, Fuori! (Italia), febrero-marzo de 1980, vol. 9, núm. 24, p. 20; Kiss of the spider woman, Body Politic (Toronto, Canadá), octubre de 1980, núm. 67, p. 37; Manuel Puig 2. Teil, Berliner Schwulen Zeitung (Berlín, Alemania), abril-mayo de 1980; Manuel Puig, Lampiao (Río de Janeiro, Brasil), junio-agosto de 1980, vol. 3, núm. 27; Archives of Sexuality \& Gender, en GALE.

54 “Interview", Gay Sunshine: A Journal of Gay Liberation, invierno de 1975-1976, p. 7, en GALE.

${ }^{55}$ Carol, "Conference Ignores Lesbians", Big Mama Rag, vol. 3-A, núm. 7, 1975, pp. 8-9, en GALE. 
Respecto a los traductores nos referimos a personajes nómadas, políglotas e inquietos que construyeron circuitos. Juan Jacobo Hernández, principal líder del FHAR, licenciado en Letras y profesor universitario, se forjó al calor de los movimientos sociales de las décadas de 1950 y 1960 . Su poder adquisitivo le permitió viajar en numerosas ocasiones a Nueva York y San Francisco en los que pudo seguir de cerca el desarrollo de los movimientos de liberación gay. ${ }^{56}$ Colaboró con el FLHM, viajó a Estados Unidos y Centroamérica en busca de aliados, en 1979 organizó un taller con el Bloque Homosexual Latinoamericano, el Comité Homosexual Latinoamericano (Nueva York), el Movimiento de Liberación Homosexual (Costa Rica) y el grupo Gay Cactus. ${ }^{57}$ Asimismo, desempeñó un papel clave en los vínculos locales con grupos trotskistas, sindicatos y feministas.

Eran traductores de experiencias que se escurrían entre lo íntimo y lo público. Luis González de Alba (1944-2016), quien después de 1968 se exilió en Chile, Argentina y Brasil, desempeñó un papel clave en la publicación de la proclama "Contra la práctica del ciudadano como botín policiaco" para cuestionar la represión a homosexuales. Se involucró en los grupos de liberación homosexual y como tal funcionó como el nexo directo entre las experiencias álgidas de 1968 y los nuevos agrupamientos homosexuales.

Los extranjeros, como Allen Young, un influyente traductor y exportador de las ideas de liberación homosexual estadunidense, periodista y fundador de numerosos periódicos, se ocupó en particular de investigar los crímenes contra homosexuales perpetuados por la revolución cubana. El FLHA tradujo algunos de sus artículos y también los del grupo Black Panthers, en los que se demandaba una perspectiva socialista sin opresión sexual. ${ }^{58}$ En 1981 publicó un libro en el condensó las críticas de los homosexuales a la opresión desplegada por la revolución cubana (Young, 1981).

En síntesis, en este apartado demarcamos las redes, prácticas y traductores globales en la formación de una política de liberación homosexual en Argentina y México.

\footnotetext{
56 Entrevista a J. J. H., 6 de noviembre de 2018.

57 FHAR informa, núm. 1, 1979, en CAMENA-UACM.

58 Allen Young, "Más de Cuba. Algunas de las razones por las que no nos callaremos", Somos, núm. 5, s. f., [diciembre de 1974], pp. 6-10, Buenos Aires.
} 


\section{TENSIONES TRANSNACIONALES: CULTURAS LOCALES, HOMONACIONALISMOS Y ANTIIMPERIALISMOS}

La demanda por la liberación homosexual no formó un todo homogéneo. Las ideas, lenguajes y vínculos que unieron las acciones de activistas en todo el mundo estuvieron mediadas por múltiples tensiones en la definición de un horizonte político. Aunque cuando Zahra Fuad proclamó a Sydney que los homosexuales no tenían patria, las sociabilidades sexuales disidentes, sus incursiones en el mundo público y las mediaciones culturales con las que constituyeron su identidad fueron muy distintas.

El primer punto de tensión se acumuló en torno a la globalización de la identidad gay. Las críticas políticas a las formas de interpretar la identidad fue elemento decisivo de los activistas nómadas argentinos que escaparon de la dictadura. A pesar de su importante influencia en Brasil, Néstor Perlongher cuestionó su acercamiento al término gay con el que creía ingresaban a un universo snob de las capas medias (Perlongher, 2014). Héctor Anabitarte vio en la identidad de consumo de los gays españoles un signo de la pérdida de radicalidad en desmedro de la transgresión homosexual frente a la que llamaba a resistirse para "no renunciar a la utopía". ${ }^{59}$ En una postura romántica afirmó que el consumismo se expresaría en la búsqueda constante de encuentros sexuales efímeros y el rechazo a construir un vínculo de pareja. ${ }^{60}$

La crítica de los argentinos a las interpretaciones "reformistas" de la homosexualidad fue constante. Cuestionaron algunas de las apreciaciones de sus pares en Holanda cuando después de una visita notaron la aparente integración de su sociabilidad como una sexualidad más y señalaron que eso se lograba a costa de transformar las formas de vida de sus periferias coloniales en despreciables. ${ }^{61}$ En una carta que enviaron a Fuori! en 1973, también destacaron que los grupos nórdicos parecían adaptarse a los principios de las religiones nacionales. ${ }^{62}$

Este rechazo no era sólo una propiedad de los argentinos, la radicalidad depositada en la homosexualidad como identidad antagónica al capitalismo

59 "No renunciar a la utopia", Gay Hotsa, 1982, en GALE.

${ }^{60}$ Lorenzo, Ricardo y Héctor Anabitarte, "Opinio", Lambda, enero de 1982, en GALE.

${ }^{61}$ Viva, "París no es el centro del mundo", Somos, núm. 5, s. f. [diciembre de 1974], pp. 30-31, Buenos Aires.

${ }_{62}$ "Frente de Liberación Homosexual de la Argentina", Fuori!, núm. 11, 1973, p. 8+, en GALE. 
proliferó también entre sus pares del norte. El grupo británico Gay Left interpretó al activismo mexicano desde una posición pendular entre el romanticismo y la asimetría. Los definieron como la expresión de los "movimientos que nacieron en los países capitalistas avanzados" y "una esperanza", puesto que por "el sistema de género más rígido" tenían una perspectiva revolucionaria y socialista que se distanciaba de "la dirección reformista del movimiento gay internacional con base en EE.UU”. ${ }^{63}$ La progresiva transformación de la capacidad de asimilación de las capitales occidentales a la sociabilidad gay marcó un giro en las agendas políticas que tendieron a poner el foco en los derechos civiles, así el grupo británico encontró en el "atraso mexicano" la esperanza a sus intentos de mantener una identidad homosexual radicalizada. ${ }^{64}$

Las referencias en las narrativas anglosajonas sobre sus aportes a la liberación homosexual en Latinoamérica se definieron desde el principio de la desigualdad en el avance en materia de derechos. En torno a la Conferencia Internacional de la Mujer de 1975, las lecturas de este tipo proliferaron destacando que fue gracias a su aporte que las lesbianas pudieron pronunciarse públicamente, ${ }^{65}$ aunque dos años antes Nancy Cárdenas ya se había presentado como lesbiana en la televisión y en los periódicos.

Este tipo de interpretaciones giraron sobre las capacidades de imaginar su identidad no sólo en relación con una comunidad global, sino con un fuerte arraigo local. A pesar de que se ha destacado el carácter cosmopolita de la identidad gay (Garrido, 2017), las perspectivas desde las metrópolis centrales del capitalismo occidental desplegaron también interpretaciones homonacionalistas. La integración progresiva mediante la ampliación de derechos civiles y la consolidación de la identidad gay como un vector del marcado neoliberal construyó un vínculo específico con la construcción moderna del Estado-nación que se instaló parcial y progresivamente en discursos liberacionistas (Puar, 2017).

El juego de solidaridades no siempre fue armónico. Frente a la guerra por las Malvinas declarada por el régimen castrense argentino, grupos británicos indicaron que "Los gays sufrirán una represión severa si los argentinos toman las Falklands." De esta forma reprodujeron un comunicado del

${ }^{63}$ Gay Left, núm. 10, 1980.

${ }^{64}$ Gay Left, núm. 10, 1980.

${ }^{65}$ Miki Sharron, "U. N. Mexico City conference: A farce from beginning to end", Sister, 1975, p. 2; Carol, "Conference ignores lesbians", Big Mama Rag, vol. 3-A, núm. 7, 1975, pp. 8-9, en GALE. 
FLHA para señalar la represión del sistema legal argentino, como fundamento, para apoyar a sus tropas. ${ }^{66}$ Gay News denostaba la soberanía argentina y se preguntaba quién querría vivir bajo su sexualidad ${ }^{67}$ a su vez se declaraban orgullosamente británicos. ${ }^{68}$ Una posición contraria a la que asumió Néstor Perlongher desde el exilio, quien entendió al Estado-nación como la apoteosis de la comunidad patriarcal nacional en ensayos como "Todo el poder a Lady Di" o "El deseo de unas islas", en los que se pronuncia como antibelicista y anti-nacionalista (Garrido, 2017).

Por las dificultades de integración como ciudadanos, los activistas argentinos y mexicanos construyeron discursos ambivalentes con los que disputaron los imaginarios nacionales. La construcción de los Estados modernos en Latinoamérica asumió al varón de elite (generalmente blanco o mestizo) como figura del ciudadano modelo, mediante el contraste de múltiples representaciones entre los que los homosexuales y lo femenino ocuparon un lugar relevante (Bao, 1993; Irwin, 2000). La emergencia de los movimientos de liberación homosexual implicó una disputa por el sentido del componente masculino de la nación. Por ejemplo, el discurso del FLHA amalgamó un intento de inserción en el ideario de una liberación más amplia frente en la que el campo de la izquierda se definía frente a otro (el imperialismo/oligarquía local), es decir, un intento de que sujetos feminizados ingresaran a un "pueblo" representado como masculino. A su vez, el rechazo a la represión estatal como las críticas a las referencias de Perón como "padre" del pueblo implicó un distanciamiento de la liturgia nacional androcéntrica (Simonetto, 2017) (véase imagen 4).

Reinventar la identidad homosexual suponía desafiar el relato nacional, el FHAR se presentó asimismo como valiente al asumirse públicamente como homosexuales en un país "en el que todos tienen que ser muy machos". ${ }^{69}$ La manifestación de la dignidad homosexual en 1979 expresó la reapropiación de términos estigmatizados como el de "lilo", "homosexual" y la apelación a lo "gay" como un signo del cosmopolitismo. A su vez, la demanda de "no hay libertad política sin libertad sexual" implicaba un intento de disputa del incipiente proceso de democratización política. Así, por ejemplo, la apelación a imágenes clásicas de la cultura estética del régimen posrevolucionario, como

66 "Gays face severe repression if Argentina takes falklands", Out! New Zealand's Alternative Lifestyle Magazine, junio-julio de 1982.

67 "Gay news", Gay News, Londres, abril 29-mayo 12 de 1982, p. 1, en GALE.

68 "At harpoon louie's", Gay News, Londres, mayo 13-26 de 1982, p. 18, en GALE.

${ }^{69}$ Política Sexual, núm. 1, 1978, FHAR, en ACHA. 


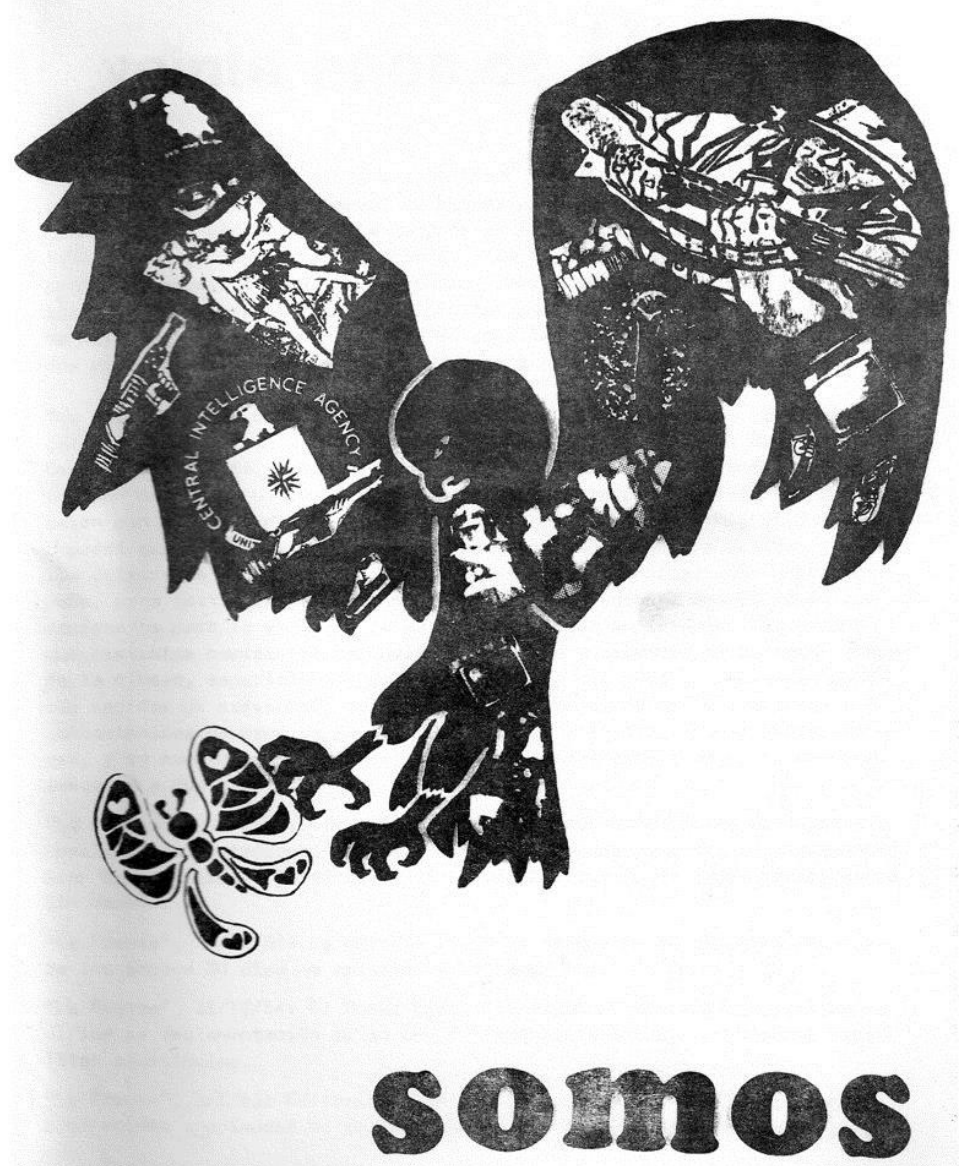

Imagen 4. Somos, núm. 5, 1974, Buenos Aires.

la estampa popular, eran utilizadas para señalar aquellos vocablos que, por un lado, los "oprimían", pero de los cuales también pretendían apropiarse. El primer punto de su declaración de principios reclamaba sus derechos democráticos y constitucionales como "ciudadanos mexicanos que somos", ${ }^{70} \mathrm{e} \mathrm{iba}$ acompañada también por arte mural mexicano, una de las iniciativas pictóri-

70 Política Sexual, núm. 1, 1978, FHAR, en ACHA. 
cas más fuertes impulsadas por el Estado con la que se reescribió la historia de México redefiniendo las representaciones del pueblo y la nación (Monsiváis, 2010) (véase imagen 5).

Las tensiones en la definición de lo político excedieron los vínculos con movimientos gay europeos o estadunidenses. El novedoso apoyo que recibieron las organizaciones mexicanas por parte de la izquierda, especialmente la trotskista, implicó cuestionamientos. La elección del fHAR de la demanda "Por un socialismo sin sexismo", era parte de una crítica a las políticas de restricción a los homosexuales aplicados en los países bajo la órbita del socialismo real. Imaginar una revolución era también pensar los sujetos posibles de aquella transformación, la referencia al proletariado industrial varón o la figura viril del guerrillero como eje del cambio revolucionario tenía como contraparte las restricciones a otras estéticas y prácticas políticas.

En el primer congreso convocado por el FHAR en 1981 llegaron adhesiones de aliados internacionales del PRT. El periódico The Torch (Nueva York) celebró la organización y la perspectiva de los colectivos mexicanos, pero fue crítico con lo que consideraba "graves errores" en su orientación. Primero cuestionó la resistencia de algunos de sus miembros a votar una "teoría marxista" general y una demanda de socialismo por considerarlo "demasiado ideológico". Además, demandaron al grupo una ampliación de su composición de clase, pidieron que hubiese "más personas trabajadoras, en especial mujeres" y sostuvieron que un grupo "compuesto por hombres de clase media no podrá unir su análisis a una revolución de clase". ${ }^{71}$

Los bloqueos y límites del FLHA para integrarse al peronismo y al campo de la izquierda también estuvieron marcados por las imaginaciones políticas de los sujetos de la revolución. No sólo se hicieron eco de las críticas a la represión a homosexuales promovidas en Cuba y la URSS, sino que cuestionaron la forma misma en la que la liberación era representada. En "El prejuicio contra el afeminamiento: una concepción machista", el FLHA sostenía que "REVOLUCIÓN es una palabra bastante manoseada y desvirtuada por significados que están cada vez más lejanos de su sentido original” y la definía como "una transformación permanente de estructuras e individuos, proceso cuyo eje central pasa por el cuestionamiento crítico. Cuestionar todo lo existente, incluidos nosotros mismos ya que el cambio individual es el mejor comienzo

${ }^{71}$ The Torch, 15 de enero de 1981, p. 4. 


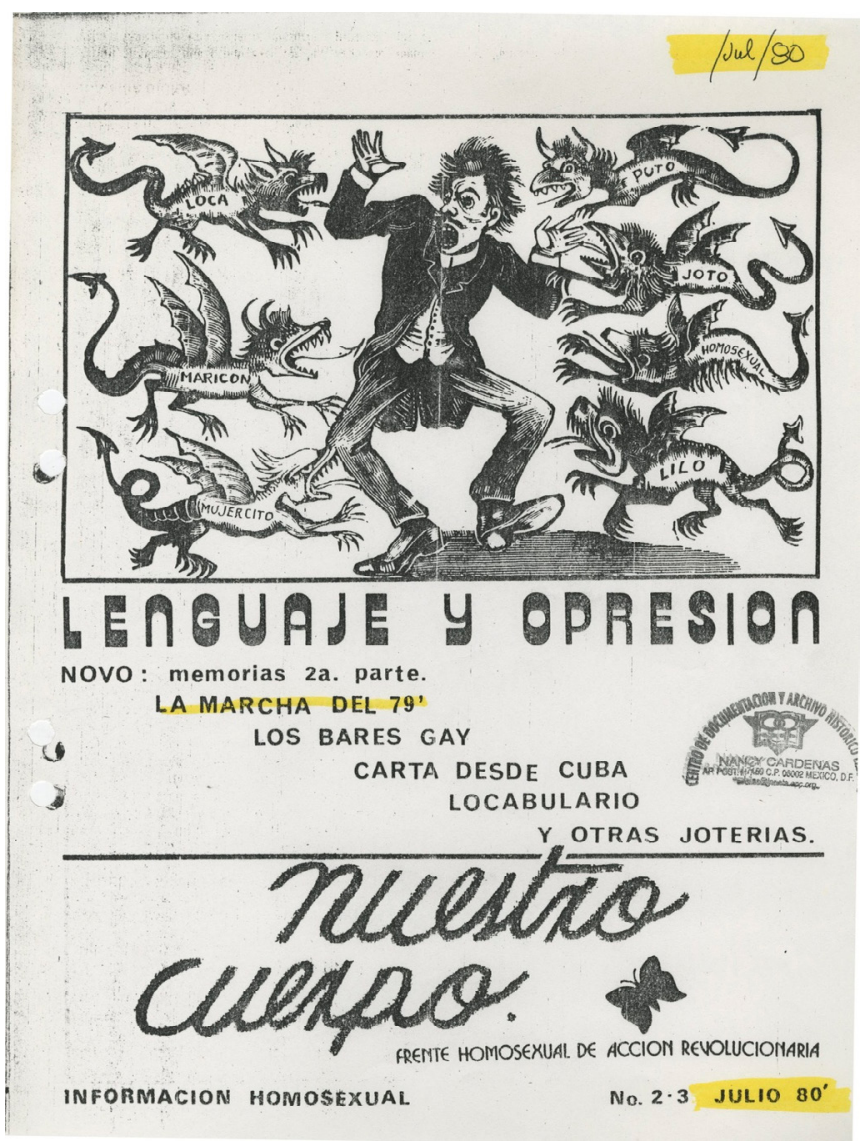

Imagen 5. Nuestro Cuerpo, núms. 2-3, 1980, en CAMENA-UACM.

para una revolución total" ${ }^{72}$ La reivindicación narrativa del afeminamiento en ilustraciones y la burla hacia la imagen idílica del varón viril promovido por la guerrilla funcionaban así como una crítica punzante hacia el corazón mismo de los horizontes de sentidos desplegados por la izquierda nacional.

Por último, entre los grupos mexicanos también existieron tensiones políticas. Aunque construyeron la Coordinadora de Grupos Homosexuales,

${ }^{72}$ Grupo de política sexual, "El prejuicio contra el afeminamiento: una concepción machista”, FLHA, 1974, en ACHA. 
junto a Lambda y OIKABETH, existieron constantes cuestionamientos al liderazgo masculino dentro del FHAR. Las pocas lesbianas del grupo intentaron hacerse visibles y cuestionar las críticas de sus adversarias, ${ }^{73}$ mientras que las activistas de Lambda -que contaban con el apoyo de Nancy Cárdenas- buscaron construir dentro de la unidad un liderazgo alternativo. Así, por ejemplo, en torno a la organización de la Segunda marcha de la dignidad homosexual, el grupo Lambda señala que tras la conferencia de prensa el FHAR intentó adueñarse de todo el crédito político de la actividad. ${ }^{74}$

\section{CONCLUSIONES}

Este texto analiza desde una perspectiva comparativa e interconectada las prácticas globales y los anclajes nacionales de la política de liberación homosexual en México y Argentina. El mismo ofrece algunas conclusiones valiosas para el estudio de las trayectorias políticas de la disidencia sexual. Primero, los activistas desplegaron múltiples prácticas para internacionalizar su política: mítines, circulación de libros, manifiestos, noticias y cartas. En este sentido, a pesar de tener una escasa vinculación en común, los puntos de contacto expresaron experiencias comunes: la represión social y estatal, la disposición de lenguajes y lecturas comunes, la dificultad por ingresar al universo de las izquierdas tradicionales -más marcado en Argentina-, la proximidad a grupos feministas $y / o$ trotskistas, $y$ las transformaciones promovidas por la globalización de la identidad gay.

Segundo, considero que la reconstrucción de traductores, contextos y redes señala el carácter poroso del micromundo del activismo homosexual. Desde los intentos de dialogar con las masas peronistas a las amistades con los trotskistas de México, la circulación de mensajes expresa los intentos por inscribir su acción política en una noción de solidaridad que trasvasaba las prácticas del "internacionalismo". Pero a pesar de sus capacidades para flexibilizarlo estas alianzas no derivaron en una integración plena en el universo político de las izquierdas y, por último, las tensiones en la definición de un sujeto político de la transformación social radical esperadas por estos grupos, las acusaciones cruzadas o las expectativas desbordantes forman parte de un

\footnotetext{
73 FHAR informa, núm. 1, 1979, en CAMENA-UACH.

74 "La segunda marcha del orgullo gay", Lambda, 1981.
} 
periodo de profuso debate en las izquierdas. La observación en estas culturas nos permite entrever las dificultades por la definición de identidades homogéneas. La globalización de la forma de vida gay se encontró así con sujetos reticentes que abrazaron el discurso de la homosexualidad como la contracara del consumo y la integración, pero el gesto de resistencia minoritario no logró impregnar en amplias franjas sociales de disidentes sexuales que reinventaron sus identidades al calor de un nuevo fenómeno cultural que marcó las décadas posteriores.

\section{LISTA DE REFERENCIAS}

25 to 6 Baking \& Trucking Society (1972). Great gay in the morning!: One group's approach to communal living and sexual politics. Washington, N.J.: Times Change Press.

Acevedo, Z. (1985). Homosexualidad: hacia la destrucción de los mitos. Buenos Aires: Ediciones del Ser.

Altman, D. (1996). Coming out in the seventies. Hong Kong: Wah Cheong Printing Press.

Altman, D. (2002). Global sex. Chicago, Il: University of Chicago Press.

Aubrey, W. (1980). Come together: The years of gay iberation (1970-73). Londres: Gay Men's Press.

Bao, D. (1993). Invertidos sexuales, tortilleras, and maricas machos: The construction of homosexuality in Buenos Aires, Argentina, 1900-1950. Journal of Homosexuality, 24(3-4), 183-220. DoI: https://doi.org/10.1300/J082v24n03_14

Barba, S. (21 de julio, 2017). Una entrevista con Gabriela Cano. Letras Libres. Recuperado de http://www.letraslibres.com/mexico/historia/una-entrevista-gabriela-cano

Barilli, G. R. (1999). Il movimento gay in Italia. Milano: Feltrinelli Editore.

Bell, A. (1971). Dancing the gay lib blues a year in the homosexual liberation movement. Nueva York: Simon and Schuster. Recuperado de http://books.google.com/ books?id=uzqGAAAAIAAJ

Bell, A. P., Weinberg, M. S., Indiana University e Institute for Sex Research (1979). Homosexualities: A study of diversity among men and women. Londres: Mitchell Beazley.

Ben, P. e Insausti, J. (2017). Dictatorial rule and sexual politics in Argentina: The case of the Frente de Liberación Homosexual, 1967-1976. Hispanic American Historical Review, 97(2), 297-325. DoI: https://doi.org/10.1215/00182168-3824077 
Boggan, E. C., Haft, M. G., Lister, C., Rupp, J. P. e Stoddard, T. B. (1983). The rights of gay people. Nueva York, NY: Discus Books.

Bosch, A. y Frente Homosexual de Acción Revolucionaria (1979). Documentos contra la normalidad. Barcelona: Bosch, Casa Editorial.

Brohm, J.-M., Brückner, P., Dahmer, H., Fernbach, D., Gartheret, F., Jervis, G. et al (1973). Marxismo, psicoanálisis y sexpol (t. 2: Estado actual de la discusión). Frankfurt am Main: Granica.

Cano, G. (1996). Más de un siglo de feminismo en México. Debate Feminista, 14, 345360.

Cassidy, J. y Stewart-Park, A. (1977). We're here conversations with lesbian women. Londres y Nueva York: Quartet Books.

Copi (2010). La guerra de las mariconas. Buenos Aires, Argentina: El Cuenco de Plata.

Cosse, I. (2014). Infidelities: Morality, revolution, and sexuality in left-wing guerrilla organizations in 1960s and 1970s Argentina. Journal of the History of Sexuality, 23(3), 415-450. DoI: https://doi.org/10.7560/JHS23304

Davis, N. Z. y Luna, P. M. (2013). Descentralizando la historia: relatos locales y cruces culturales en un mundo globalizado. Historia Social, 75, 165-179.

Dehesa, R. de la (2010). Queering the public sphere in Mexico and Brazil: Sexual rights movements in emerging democracies. Durham: Duke University Press.

D'Emilio, J. (2014). In a new century: Essays on queer history, politics, and community life. Madison: University of Wisconsin Pres.

Diez, J. (2011). La trayectoria política del movimiento lésbico-gay en México. Estudios Sociológicos, 29(86), 687-712.

Duflot, J. (1971). Conversaciones con Pier Paolo Pasolini. Barcelona: Editorial Anagrama.

Drayton, R. y Motadel, D. (2018). Discussion: the futures of global history. Journal of Global History, 13(1), 1-21.

Eck, M. y Mok, M. (1969). Homoseksualiteit. Antwerpen: Het Spectrum.

Felitti, K. (2018). De la "mujer moderna" a la "mujer liberada”. Un análisis de la revista Claudia de México (1965-1977). Historia Mexicana, 67(3), 1345-1393. DoI: https:// doi.org/10.24201/hm.v67i3.3531

Foster, M. y Murray, K. (1972). A not so gay world. Toronto: McClelland and Stewart. Garrido, G. (2017). La Internacional Argentina: las cosmopolíticas queer de Copi, María Moreno y Néstor Perlongher (1971-1992). (Tesis de doctorado). New York University.

Garskof, M. H. (1971). Roles women play readings toward women's liberation. Brooks/Cole Pub. Co. 
Gay Academic Union, New York Chapter y Scholarship Committee (eds.) (1985). Homosexuality, intolerance, and christianity: a critical examination of John Boswell's work. New York City: Scholarship Committee, Gay Academic Union.

Gleibman, S. (2017). "The madness of the carnival": Representations of Latin America and the Caribbean in the U. S. Homophile Press. Journal of Homosexuality, 64(7), 870-888. DOI: https://doi.org/10.1080/00918369.2017.1280989

Green, J. N. (2001). Beyond carnival: Male homosexuality in twentieth-century Brazil. Chicago y Londres: University of Chicago Press.

Green, J. N. (2012). "Who is the macho who wants to kill me?" Male homosexuality, revolutionary masculinity, and the Brazilian armed struggle of the 1960s and 1970s. Hispanic American Historical Review, 92(3), 437-469.

Grier, B. y Reid, C. (1976). The lesbians home journal: stories from the ladder. Baltimore: Diana Press. Recuperado de http://books.google.com/books?id=tflQAQAAIAAJ

Guerin, D. (1969). Kinsey y la sexualidad. Buenos Aires: La Pleyade. Recuperado de https://www.worldcat.org/title/kinsey-y-la-sexualidad/oclc/802610117\&referer= brief_results

Healey, D. (2002). Homosexual existence and existing socialism: New light on the repression of male homosexuality in Stalin's Russia. GLQ: A Journal of Lesbian and Gay Studies, 8(3), 349-378.

Hilderbrand, L. (2013). A suitcase full of Vaseline, or travels in the 1970s gay world. Journal of the History of Sexuality, 22(3), 373-402.

Hocquenghem, G. (1974). Homosexualidad y sociedad represiva. París: Garnica.

Humphreys, L. (1972). Out of the closets: the sociology of homosexual liberation. Englewood Cliffs, N. J.: Prentice-Hall.

In the spirit of stonewall (1979). Atlanta: World View Publishers.

Irwin, R. M. (2000). THE FAMOUS 41: The scandalous birth of modern Mexican homosexuality. GLQ: A Journal of Lesbian and Gay Studies, 6(3), 353-376. DoI: https://doi.org/10.1215/10642684-6-3-353

Jay, K. y Young, A. (1992). Out of the closets: voices of gay liberation. Nueva York: New York University Press.

Keller, R. (2015). Mexico's cold war. United Kingdom: Cambridge University Press.

Laguarda, R. (2007). Gay en México: lucha de representaciones e identidad. Alteridades, 17(33), 127-133.

Laguarda, R. (2008). ¡Tenemos un mundo por ganar! Visiones militantes de las homosexualidades masculinas en la ciudad de México. Historia y Grafía, 31. Recuperado de http://www.redalyc.org/resumen.oa?id=58922941006 
Laguarda, R. (2010). Ser gay en la ciudad de México: lucha de representaciones y apropiación de una identidad, 1968-1982. México: Instituto Mora.

Laguarda, R. (2018). ¿Una huella indeleble? La apropiación de 1968 desde la liberación gay en la ciudad de México. En D. Cejudo y M. Santiago (eds.), Revisitando el movimiento estudiantil de 1968. La historia contemporánea y del tiempo presente en México. México: unAm.

Leyland, W. (1979). Now the volcano: an anthology of Latin American gay literature. San Francisco: Gay Sunshine Press.

Lizarraga, X. (1978). El homosexual ante la sociedad enferma (vol. 25). Barcelona: Tusquets.

Loss, J. (2005). Cosmopolitanisms and Latin America: against the destiny of place. Nueva York: Palgrave.

Macías-González, V. M. (2015). The transnational homophile movement and the development of domesticity in Mexico City's homosexual community, 1930-70. En Gender, imperialism and global exchanges (pp. 132-157). Wiley-Blackwell. DoI: https://doi.org/10.1002/9781119052173.ch6

Marchesi, A. (2017). Escribiendo la guerra fría latinoamericana: entre el sur "local" y el norte "global". Estudos Históricos, 30(60), 187-202. DoI: https://doi.org/10.1590/ s2178-14942017000100010

Marcuse, H. (1972). Eros y civilización. Barcelona: Seix Barral.

Masters, R. E. (1964). The homosexual revolution. Belmont Books.

Masters, W. H. y Johnson, V. E. (1982). Homosexuality in perspective. Nueva York: Bantam Books.

McCubbin, B. (1979). The gay question: a marxist appraisal. Nueva York: World View Publishers.

Mieli, M. y Jordá, J. (1979). Elementos de una crítica homosexual. España: Anagrama.

Millett, K. (1972). Sexual politics. Londres: Abacus.

Milligan, D. (1973). The politics of homosexuality. Londres: Pluto Press.

Mitchell, L., Asta, N. y Calamus Books (1988). The faggots \& their friends between revolutions. Nueva York, N. Y.: Calamus Books.

Mogrovejo, N. (2000). Un amor que se atrevió a decir su nombre: la lucha de las lesbianas y su relación con los movimientos homosexual y feminista en América Latina. México: Plaza y Valdés.

Monsiváis, C. (1994). Envío a Nancy Cárdenas, activista ejemplar. Debate Feminista, 10, 257-263.

Monsiváis, C. (2010). Historia mínima. La cultura mexicana en el siglo xx. México: El Colegio de México.

Moyn, S. (2012). The last utopia. Cambridge y Londres: Harvard University Press. 
Murphy, J. (1971). Homosexual liberation a personal view. Nueva York: Praeger Publishers. Recuperado de http://books.google.com/books?id=9lpCAAAAIAAJ

Nichols, J. (1980). Men's liberation: a new definition of masculinity. Harmondsworth: Penguin.

Nicolas, J. (1982). La cuestión homosexual. Barcelona: Fontamara. Recuperado de https://www.worldcat.org/title/cuestion-homosexual/oclc/1055277931\&referer= brief_results

Paniagua García, J. A. (2017). Néstor Perlongher: los años de formación intelectual (1968-1978). Castilla. Estudios de Literatura, 8, 229-356. DoI: https://doi.org/10.24197/ cel.8.2017.339-356

Palmeiro, C. (2011). Desbunde y felicidad: de la Cartonera a Perlongher. Buenos Aires: Mansalva.

Parker, W. y Parker, W. (1977). Homosexuality bibliography: supplement, 1970-1975. Metuchen, N. J.: Scarecrow Press.

Pensado, J. M. y Ochoa, E. C. (2018). México beyond 1968: Revolutionaries, radicals, and repression during the global sixties and subversive seventies. Tucson: University of Arizona Press.

Perlongher, N. O. (1999). El negocio del deseo: la prostitución masculina en San Pablo (vol. 3). Buenos Aires: Paidós.

Perlongher, N. O. (2014). Néstor Perlongher. Correspondencia. Recuperado de https:// mansalva.com.ar/producto/perlongher/ [consulta: 30 de octubre de 2018].

Prado, M. L. C. (2013). América Latina: historia comparada, historias conectadas, historia transnacional. Anuario de la Escuela de Historia, 24, 9-22.

Puar, J. K. (2017). Ensamblajes terroristas: el homonacionalismo en tiempos queer. Barcelona: Bellaterra.

Radius, E. (1970). La revolución de la mujer. Barcelona: Plaza y Janés.

Reich, W. (1972). La lucha sexual de los jóvenes. Buenos Aires: Granica Editores.

Richmond, L. y Noguera, G. (1979). The new gay liberation book: writings and photographs about gay (men's) liberation. Palo Alto, California: Ramparts Press.

Rodríguez Sánchez, N. (2018). De Cuauhtemotzin a las cervecerías. El control oficial del homoerotismo masculino y la construcción estratégica de la geografía disidente, ciudad de México 1930-1951. Historia Mexicana, 68(1), 111-176. DoI: http:// dx.doi.org/10.24201/hm.v68i1.3639

Rojas, R. (2016). Traductores de la utopía: La revolución cubana y la nueva izquierda de Nueva York. Fondo de Cultura Económica.

Romero, F. C. C. C. y Simonetto, P. (2019). Sexualidades radicales: los movimientos de liberación homosexual en América Latina (1967-1989). Izquierdas, 46 (46), 65-85. 
Rowse, A. L. y Liaras Muls, E. (1988). Homosexuales en la historia: estudio de la ambivalencia en la sociedad, la literatura y las artes. México: Planeta.

Rupp, L. J. (2011). The persistence of transnational organizing: The case of the homophile movement. The American Historical Review, 116(4), 1014-1039. DoI: https:// doi.org/10.1086/ahr.116.4.1014

Scheider, A. (2006). Los compañeros. Trabajadores, izquierda y peronismo 1955-1973. Buenos Aires: Imago Mundi.

Scheuzger, S. (2018). La historia contemporánea de México y la historia global: reflexiones acerca de los "sesenta globales". Historia Mexicana, 68(1), 313-358. DoI: https://doi.org/10.24201/hm.68il.3645

Simonetto, P. (2016). La moral institucionalizada. Reflexiones sobre el Estado, las sexualidades y la violencia en la Argentina del siglo xx. El@tina. Revista Electrónica de Estudios Latinoamericanos, 14(55), 1-22.

Simonetto, P. (2017). Entre la injuria y la revolución: el Frente de Liberación Homosexual. Argentina, 1967-1976. Buenos Aires: Universidad de Quilmes.

Simonetto, P. (2018). Intimidades disidentes. Intersecciones en las experiencias de homosexuales y lesbianas en Buenos Aires durante los sesenta y setenta. Trashumante: Revista Americana de Historia Social, 11, 28-50. DoI: https://doi.org/10.17533/ udea.trahs.n11a02

Simons, R. (1965). De maatschappelijke en sociaal-medische betekenis van de homofilie en het v'o'orkomen van geslachtsziekten onder homofielen (naar aanleiding van een onderzoek bij ruim 100 personen). Geneeskundige Gids, 43, 1-20.

Smith, D. E. (1977). Feminism and marxism: a place to begin, a way to go. Vancouver: New Star Books.

Sylvestre, P.-F. (1979). Les homosexuels s'organisent au quebec et ailleurs. Montreal: Editions Homeureux.

Trebisacce, C. y Mangiantini, M. (2015). Feminismo, diversidad sexual y relaciones sexo-afectivas disidentes. Apuestas y tensiones en el PST, 1971-1975. Archivos, 4(7), 101-120.

Ussel, J. van. (1974). La represión sexual. México: Ed. Roca.

Valdiosera, R. (1973). El lesbianismo en México. México: Clásico Pendulum.

Vaughan, M. K. (2014). Portrait of a Young Painter: Pepe Zúñiga and Mexico City's Rebel Generation. Duke University Press.

Vespucci, G. (2011). Explorando un intrincado triángulo conceptual: homosexualidad, familia y liberación en los discursos del Frente de Liberación Homosexual de Argentina (FLH, 1971-1976). Historia Crítica, 43, 174-197. 
Weeks, J. (1991). Coming out: homosexual politics in Britain from the nineteenth century to the present. Londres y Nueva York: Quartet Books.

Weeks, J. y Rowbotham, S. (1978). Dos pioneros de la liberación sexual: Edward Carpenter y Havelock Ellis. Barcelona: Anagrama.

Wolf, D. G. (1980). The lesbian community. Berkeley: University of California Press.

Young, A. (1981). Gays under the Cuban revolution. Nueva York: Grey Fox Press.

Zolov, E. (1999). Refried Elvis: The rise of the Mexican counterculture. Oakland, CA: University of California Press.

\section{OTRAS FUENTES}

Archivos

ACHA

Archivo Comunidad Homosexual Argentina.

CAMENA-UACM

Centro Académico de la Memoria de Nuestra América. Universidad Autónoma de la Ciudad de México.

GALE Archives of Sexuality \& Gender, en https://www.gale.com/

\section{Hemerografía}

Así, Argentina.

Diario de México, México.

El Sol de México, México.

Gay Left, Reino Unido.

Lambda, México.

Nuestro Cuerpo, México.

Oaxaca Noticias, México.

Out! New Zealand's Alternative Lifestyle Magazine, Nueva Zelanda.

Siempre!, México.

Somos, Argentina.

Tacuara, Argentina.

The Torch, Nueva York.

Unomásuno, México. 